\title{
Sinónimos e antónimos, com design sueco Göteborg Dance and Theatre Festival 2004
}

\section{Mónica Guerreiro}

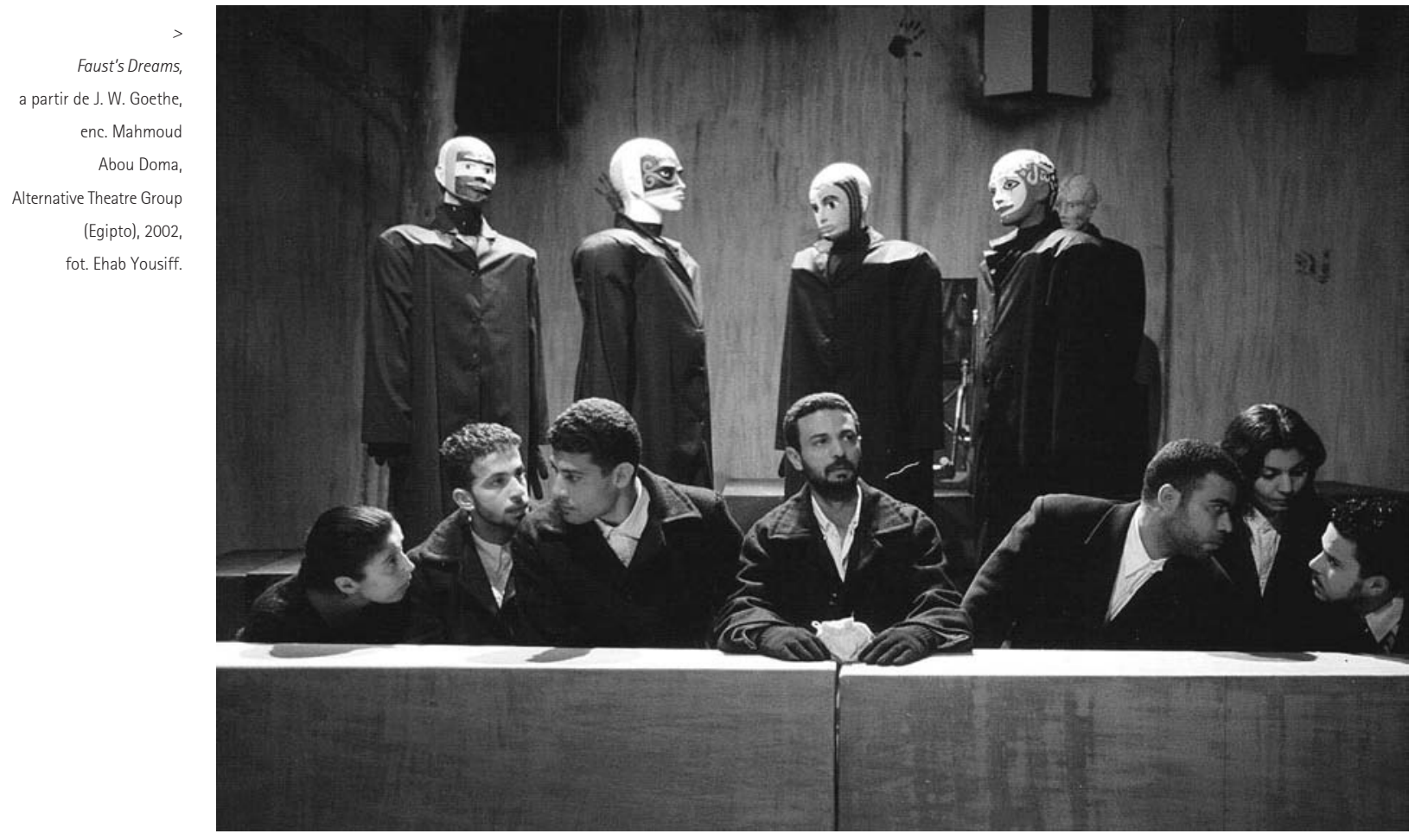

Dança contemporânea, teatro, novo circo e live art. 0 festival internacional da segunda cidade sueca tem como prioritários estes territórios da experimentação cénica, no sentido de privilegiar os cruzamentos: entre disciplinas, entre práticas mais devedoras da tradição e outras que absorvem da experiência contemporânea a sua especificidade. Birgitta Winnberg-Rydh, directora artistica, optou por delinear um programa quase excessivo na quantidade de espectáculos, conferências, seminários, conversas informais (pequenos-almoços, na verdade) e workshops - tanto que seria dificil reconhecer na mais recente edição do Göteborg Dance and Theatre Festival (GDTF) um carácter de mostra ou de "aperitivo" para o que de mais estimulante se produz, por esse mundo fora nas áreas artísticas referidas. Em Gotemburgo, serviu-se a refeição completa. Com direito a digestivo: a ambiciosa montra (ou hipermercado) de arte escandinava que, ao longo de três dias non-stop, permitiu conhecer o trabalho de quatro dezenas de artistas que constituirão a Nordic Excellence (assim se intitulava o evento). Entre muitos nomes desconhecidos (além de impronunciáveis), encontrámos pelos quatro palcos um ou outro já familiar como os noruegueses Baktruppen (apresentaram em Lisboa a peça Very Good, no âmbito do Capitals - Encontros Acarte 2003). Mas reduzir o GDTF a este "festival dentro de um festival", como a organização Ihe chamou, é de uma injustiça clamorosa: durante oito dias - a última semana de Agosto - a cidade metamorfoseou-se em palco (14 espaços de apresentação) e os suecos em massivos consumidores culturais em tempo de férias.

\section{A prática..}

Alguns artistas já fizeram o eixo Lisboa-Gotemburgo: Edit Kaldor com o seu reputadíssimo (além de particularmente interessante) Or Press Escape; Lone Twin e a sequela do que mostraram por cá, também em Capitals, intitulado Sledge Hammer Songs; Les Ballets C. de la B. e o mui aclamado (mas não consensual) Foi; Marie Brassard já sem os sonhos de Jimmy que nos relatou no CCB há uns anos, mas com The Darkness (interpretado em inglês). 0 que mais interessará aos que lêem será talvez conhecer as investidas não destes, mas dos outros, cuja presença entre nós é mais longinqua ou nenhuma: Carlotta Ikeda e o seu exercício radical-iconoclasta Togué, cuja violência abalou as estacas do velho teatro de ópera onde se apresentou; a nova peça de Akram Khan, ma, que gera um contacto 


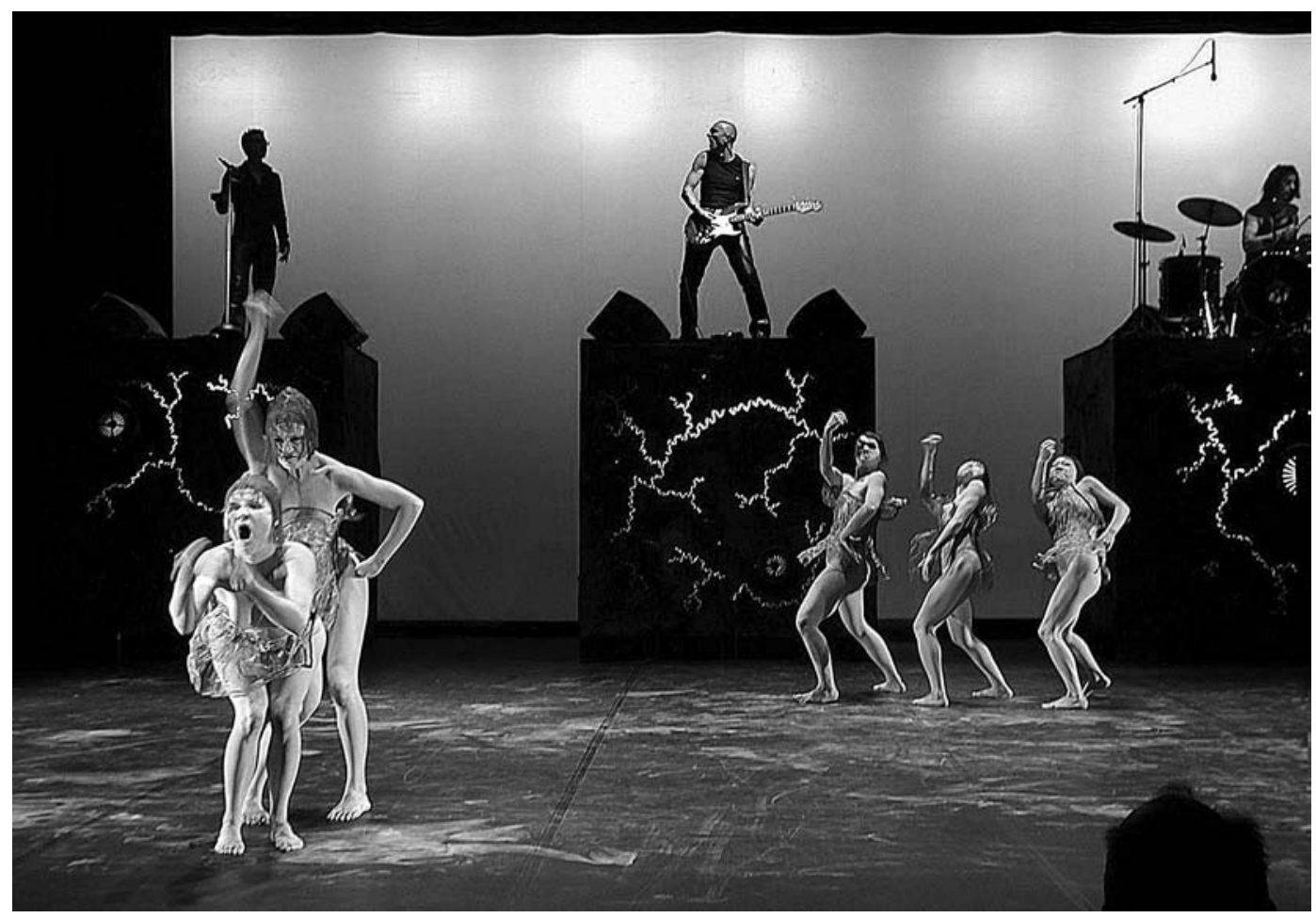

Togué,

criação de Carlotta Ikeda, Compagnie Ariadone (Japão / França), 2004, fot. Vincent Paris.

intimista rarissimo ente sete bailarinos e três músicos, e quantos mais se tenham deixado emocionar; ou a expressividade quase pueril do ensemble egipcio Alternative Theatre Group, de Mahmoud Abou Doma, cujo Faust's Dreams me fez, estranhamente, regressar a um tempo em que o teatro era a magia da interpretação embebida de vida até ao osso. Duas razões justificam esta "estranheza": por um lado, não são já realistas os pressupostos da aventura cénica na contemporaneidade e, por outro, como para espantar ainda mais os cépticos, metade dos "intérpretes" da peça são bonecos de gesso, em tamanho real, cuja concepção e disposição oferecia uma contracena fortíssima com os actores (não, não estou a endoidecer) e proporcionava à fábula, de forma para mim inédita, um outro vértice de reflexão.

Continuando nas linguagens além-Europa - parte grande do festival, curiosamente, não calhava mal numa Culturgest, com sua pertinente (e feliz) vocação de aproximar as distâncias -, falemos em maior pormenor do espectáculo que mais opiniões dividiu: o da sexagenária Carlotta Ikeda. Situado num território de ambiguidades e contrastes, Toguérevelava-se na sua evidência: uma banda francesa de rock industrial (ou algum sub-género que não soube identificar) enfrenta a rebeldia de um grupo de dançarinas de butô que, apesar do manifesto pós-feminista, continua a ostentar uma fragilidade só falsamente antagónica. 0 espectáculo - a tese que o sustenta, mesmo assim mal - é apenas isto: uma estrutura cénica em altura superioriza os homens, violentos, agressivos e uniformes, além de sombrios, e subalterniza as mulheres, delicadas, frágeis e inconstantes, que chegam até à histeria e ao desespero. Não simplifiquemos: procurou-se injectar nuances de coincidência entre os dois mundos (quando o vocalista, bastante sofrivel nessa qualidade, "desce" ao nivel feminino num diálogo de forças que acaba com Carlotta, a própria, procurando "resgatá-lo"), mas o maniqueísmo é inevitavelmente primário e inquina um espectáculo que tinha pernas para andar. Uma cenografia lindissima, além de muito funcional, e um desenho de luzes magistral não salvam o barco. Houve, porém, quem se tenha deixado fascinar pelo aparente "choque" (de gerações, das convenções, das leituras dos géneros) propiciado pelo espectáculo. Bocejo e previsibilidade, atiro eu.

0 troféu para o mais enternecedor dos espectáculos, dito isto, teve de ficar com Cirque and the Story of August, da francesa Cie. Cirque, dirigida por Ueli Hirzel. Quando 


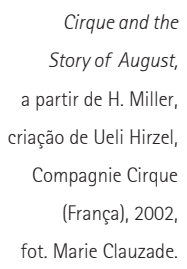

'Esta noção de

dramaturgia construida a

partir da ligação de

números ("acts") sem relação entre si é comum a algumas experiências de novo circo - expressão que, apesar de desadequada, continua a usar-se à falta de melhor termo que o distinga do circo dito tradicional.

Sobre estes e outros traços identificativos da

prática circense contemporânea, vejam-se os textos de Jean-Miche

Guy sobre a temática -

"O que é o circo? (sete definiçōes em liça)" e

"A emancipação das 'artes de circo"' - assim como a entrevista de Isabel Alves

Costa e António Ramos ao Circolando, por ora 0

mais consciente dos colectivos portugueses de artes circenses, incluidos no número 2 de Cadernos do Rivoli (Porto, 2004), dedicado especificamente a honestidade se impõe, não há como fugir-lhe: a grandeza do novo circo como disciplina, apesar das décadas de maturação do conceito, ainda não se me revelou. Mas se as produções que a essa designação se arrogam forem todas deste calibre, terei prazer em retractar-me. Livremente baseado no conto de Henry Miller 0 sorriso aos pés da escada, este foi para mim o primeiro espectáculo assumidamente circense (trapezista, malabarista, palhaços, números musicais: confirma) que toma como ponto de partida o questionamento da sua própria natureza desconexa, inútil e ostensivamente anti-contemporânea. Essa assunção do circo como tradição de exibicionismos fúteis e vazios, do carácter nómada das famílias circenses como uma coisa arcaica (além de pouco confortável) e dessas circunstâncias como uma herança nobre arcada com honra, profissionalismo e talento - as principais linhas de pensamento de que um espectador de Cirque and the Story of August não pode alhear-se - servem para a companhia montar um exercício auto-referencial, ao qual não faltam os números obrigatórios nem o devido contexto'. E "a companhia" são quatro intérpretes-criativos: os quatro intervenientes na acção (que são os únicos a fazê-la acontecer: manipulam cordas, adereços, ganchos, maças, maquilhagem, instrumentos musicais inauditos, roupagens variadas, microfones de apresentador, sapatilhas de pontas - não há mais ninguém a ajudar a calçar, a descer, a sair, a iluminar, a dar som). Um espectáculo hilariante e comovente, feito de compromisso (não de antítese) entre a tradição ("you may like or not, but there is nothing to understand") e a modernidade do (novo) circo (algo para compreender). 0 que é que se pode querer mais?

\section{... e a teoria}

Acompanhando parte substancial do GDTF, um grupo de doze jovens cidadãos no mundo - a saber: Canadá, Coreia do Sul, Dinamarca, Estados Unidos da América, França, Moldávia, Portugal, Roménia (2), Rússia, Suécia (2) - e três não-menos-jovens-em-espirito-e-cidadania monitoras escandinavas (Margareta Sörenson, directora, Lis Hellström Sveningson, crítica de dança local, e Vibeke Wern, que lecciona crítica no departamento de dança de uma universidade em Copenhaga) frequentaram o Seminário Internacional para Jovens Críticos, iniciativa da IATC / AICT, pela primeira vez destinado a jovens críticos de teatro e dança. Além da vivência social intensa que uma ocasião como esta sempre potencia, pela simples presença comum de pessoas com origens e experiências tão diversas, aquilo que de mais forte ficou como marca dessa semana de "seminarista" prende-se com a constatação da urgência que cada um tinha em expor perplexidades, resolver dúvidas, confrontar problemas, comparar práticas. E a rapidez com que as conclusões quase se nos antecipavam: cada vez menos espaço na imprensa periódica, cada vez mais pressão para que a escrita se execute em frases curtas e compreensiveis (mais soundbyte, mais infotainment, menos análise), cada vez mais empregos

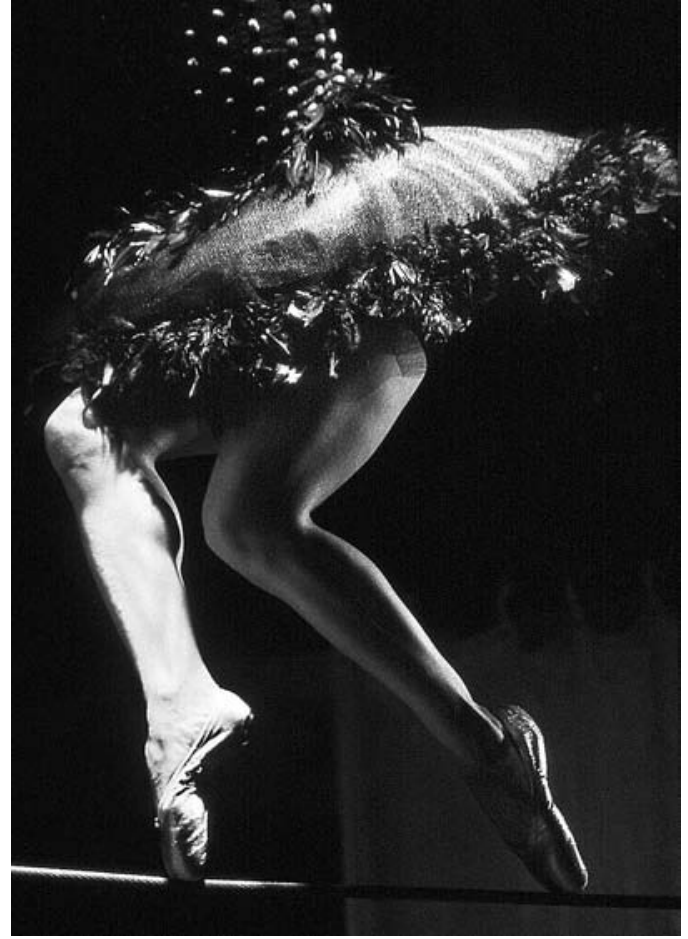

paralelos para compensar uma realidade que todos, sem excepção, testemunharam - nenhum crítico contratado nenhum crítico a tempo inteiro. Aquilo que dizem sobre a classe artística ("once an actor, always a waiter") parece ser cada vez mais verdade também acerca daqueles cujo estatuto laboral - ainda que do "outro lado da barricada" - coincide em precariedade e instabilidade.

Mas nem tudo é de lamentar: a própria existência destes encontros só pode ser um sinal da vitalidade da actividade crítica, em países - em continentes - tão diferentes entre si. E uma oportunidade para aprender, com os comissários nacionais, um pouco do que por lá se passa. Na verdade, a ausência de representação britânica ou italiana não pareceu inoportuna: em teatro, são as referências que (quase) todos partilhamos... A complexidade das geografias (sociais e artísticas) canadiana francófona, sul-coreana, da ex-URSS ou - porque não afirmá-lo? - portuguesa preencheu de curiosidade as manhãs de trabalho e discussão, que sempre terminavam cedo demais para completar o inevitável exercicio comparativo. A nova-iorquina Kerri Allen falou de fenómenos globais, como o musical The Producers, mas também de dois recentes prémios Pulitzer, Nilo Cruz e Susan Lori Parks, para explicar a crescente importância da arte de e sobre as minorias: dez anos depois de Anjos na América, começa a falar-se de reconhecimento e unanimidade. Inacreditável é a tendência de certos críticos, como o dinamarquês Johan Bröndsted ou a sueca Ann Tomic, para "ler" questões de género em praticamente todas as performances a que assistimos em conjunto: mas esse parece ser um traço comum à criação artística escandinava, que tem a capacidade de iniciar ou continuar as discussões sociais relevantes. Desemprego e feminismo parecem ser os tópicos do dia: no jornal da manhã e no espectáculo ao fim da tarde. Um teatro com contornos de vida, uma dança que ambicione dizer tudo: mais do que debater as problemáticas da crítica, os críticos reuniram-se em torno da criação, que é aliás aquilo que interessa e a que sempre regressaremos. 